\title{
LOGÍSTICA REVERSA DE RESÍDUOS DAS ATIVIDADES AGROSSILVIPASTORIS E AGROINDUSTRIAIS: UMA REVISÃO SISTEMÁTICA DA LITERATURA
}

\author{
Renato Rocha Dias Santos* \\ Patricia Guarnieri** \\ Marlon Vinícius Brisola***
}

RESUMO: A logística reversa tem se tornado uma prática bastante debatida nos ambientes organizacionais e acadêmicos e acabou se consolidando como um instrumento da Política Nacional de Resíduos Sólidos. Nas cadeias agrossilvipastoris e agroindustriais, a importância de se implantar sistemas logísticos reversos também tem ganhado relevância visto que os resíduos oriundos destas atividades tornam-se igualmente problemáticos para o meio ambiente e para a saúde humana. Diante desse cenário, o objetivo deste trabalho é identificar na literatura brasileira o estado da arte das pesquisas sobre logística reversa de resíduos gerados na atividade agrossilvipastoril e agroindustrial de modo a ilustrar como o tema tem sido abordado nas pesquisas nacionais, quais suas contribuições para ampliar esses sistemas no agronegócio e quais as lacunas de pesquisas existentes. Para atingir esse objetivo foi realizada uma revisão sistemática da literatura abrangendo publicações abrigadas nos Periódicos Capes, Banco de Teses e Dissertações da Capes, Scielo, Spell e complementarmente, no Google Acadêmico, no período de 2005 a 2016. Os resultados apontam que a produção acadêmica para logística reversa de resíduos oriundos da atividade agrossilvipastoril e agroindustrial ainda é baixa e predominam pesquisas relacionadas a embalagens de agrotóxicos pós-consumo e destinadas ao reaproveitamento de resíduos orgânicos gerados em grandes cadeias agroindustriais.

PALAVRAS-CHAVE: Logística reversa; Resíduos; Meio ambiente; Agrossilvipastoril; Agroindústria.

Mestre em Agronegócios Universidade de Brasília (UnB) e Analista de Infraestrutura da Secretaria de Agricultura Familiar e do Desenvolvimento Agrário (SEAD), Brasil. E-mail: renatoufv@bol.com.br

** Docente e Pesquisadora na Universidade de Brasília (UnB), no curso de graduação em Administração e Pósgraduação em Agronegócios. Doutora em Engenharia de Produção (UFPE), Brasil.

*** Docente e Pesquisador na Universidade de Brasília (UnB), no curso de graduação em Gestão de Agronegócios (FAV) e no Programa de Pós-graduação em Agronegócios - PROPAGA. Doutor em Ciências Sociais (UnB), Brasil. 


\section{REVERSE LOGISTICS OF WASTES FROM AGRICULTURAL- LIVESTOCK AND AGROINDUSTRY ACTIVITIES: A REVIEW OF THE LITERATURE}

ABSTRACT: Reverse logistics is a hotly debated practice in organizational and academic milieus. In fact, it has been established as a tool for the Brazilian policy of solid wastes. The importance of introducing reverse logistic system in agricultureforest-pastoral and agro-industrial activities is self-evident since wastes from such activities are crucial for the environment and for human health. Current study identifies state-of-the-art research in the literature on reverse logistics of wastes produced by agriculture-forest-pastoral and agro-industrial activities to follow approach given to the theme in Brazilian research. The latter's contribution to develop such systems in agribusiness and the gaps in current research are also investigated. A systematic review of the literature has been undertaken involving Capes Scientific Journals, Theses and Dissertations Databases, Scielo, Spell and, as a supplement, Google Academic, between 2005 and 2016. Results show that academic production for reverse logistics of wastes derived from agriculture-forest-pastoral and agroindustry activities is still scarce. On the other hand, research on postconsumption agrotoxic packages for recycling of organic residues derived from the great agro-industrial chains is predominant.

KEY WORDS: Reverse Logistics; Wastes; Environment; Agriculture-Livestock; Agroindustry.

\section{INTRODUÇÃO}

As abordagens científicas relacionadas à logística reversa têm ganhado cada vez mais espaço nas pesquisas acadêmicas e maior atenção de pesquisadores de diversas áreas de conhecimento. De acordo com Chaves e Alcântara (2009), a evolução do número de publicações evidencia que a logística reversa é uma área de pesquisa que se encontra em fase de desenvolvimento.

A ampliação dos estudos relacionados à temática mostra reflexos da relevância dada ao tema na atualidade, já que aspectos como a eficiência e o aproveitamento nos processos industriais, bem como a maximização da satisfação do consumidor são elementos essenciais ao mundo global atual. Acrescenta-se que 
as preocupações crescentes relacionadas à sustentabilidade e ao meio ambiente a respeito da geração e disposição final dos resíduos sólidos tornaram-se objeto de preocupação pública e sujeitas à regulação e normatizações específicas.

O setor agrícola brasileiro é um dos mais relevantes para a economia nacional e representa importante parcela no PIB, contribuindo com cerca de $21 \%$ do produto interno da economia no ano de 2015 (CEPEA, 2015). Dentre as atividades que vem se desenvolvendo, em grande intensidade no setor agropecuário, destacamse os sistemas agrícolas intensivos agroindustriais, o que tem colocado esse setor em posição de destaque no agronegócio tanto para o mercado interno como para a exportação (SPADOTTO; RIBEIRO, 2006).

Dessa maneira, o crescimento do setor de agronegócios aliado ao incremento de sistemas mais intensivos tem proporcionado crescentes gerações de resíduos oriundos de atividades agroindustriais e agrossilvipastoris, o que gera preocupações ambientais, mas também alimenta boas oportunidades de negócios com materiais que ainda detêm valor econômico ou energético. Alia-se a oportunidades de negócios com os resíduos agroindustriais ou agrossilvopastoris, os consideráveis ganhos sociais em retirá-los de destinações inadequadas, pois contribui para o controle da poluição e melhoria das condições de saúde pública (IPEA, 2013).

Dentre os resíduos oriundos das atividades agrossilvipastoril e agroindustrial, estes podem se dividir em duas origens: os inorgânicos, que são compostos basicamente por embalagens de agrotóxicos, de sementes e fertilizantes, frascos de produtos veterinários, sacarias, resíduos domésticos, dentre outros; e os orgânicos, gerados principalmente do processamento de biomassa vegetal e de criatórios de animais (IPEA, 2012; IPEA, 2013).

Estimativas de resíduos orgânicos gerados em agroindústrias nas principais culturas brasileiras, somente no ano de 2009, já apontavam uma produção de 291 milhões de toneladas de resíduos sólidos somente oriundos de unidades agroindustriais. Este dado já demonstra o enorme desafio para a destinação final ou aproveitamento desses resíduos no setor agropecuário mesmo não considerados os resíduos gerados diretamente na agricultura, pois são de difícil mensuração e ficam geralmente na área de produção, sujeitos a queimas e reúso no solo (IPEA, 2012).

Com relação aos inorgânicos, é crescente a geração de resíduos a cada ano em razão de atividades produtivas cada vez mais intensivas e dependentes 
de insumos externos, e dar destinação final adequada a embalagens contendo contaminantes torna-se fundamental, tendo em vista que muitos desses resíduos são classificados como perigosos com alto risco de contaminação humana e ambiental (COMETTI, 2009). Para exemplificar, somente em 2010, em torno de 30 mil toneladas de embalagens de agrotóxicos foram retiradas do campo para destinação final adequada, o que representou quase o dobro da quantidade destas embalagens retiradas no ano de 2005 (IPEA, 2013).

Implementar fluxos logísticos reversos em resíduos pós-consumo ou do processo produtivo agroindustrial podem ser considerados também como uma política pública, pois a incapacidade evidente e custos cada vez maiores de disposição final em aterros e estruturas tradicionais de tratamento estão se tornando mais onerosos e complexos, frente a crescente geração advinda de padrões de consumo mais elevados da sociedade atual. Corroboram com esse entendimento, Jacobi e Besen (2011), em que afirmam que a preocupação mundial em relação aos resíduos sólidos tem aumentado já que se têm cenários de crescimento da produção, do gerenciamento inadequado e da falta de áreas de disposição final.

Frente às questões críticas relacionadas à problemática de crescente geração e incapacidade de destinação final de resíduos, a lei no $12.305 / 10$ instituiu a Política Nacional de Resíduos Sólidos - PNRS, como evidente orientação político-institucional de Estado para incentivar os fluxos reversos de geração de resíduos e orientar os caminhos críticos para a redução, reutilização e reciclagem. O artigo terceiro da lei $\mathrm{n}^{\mathrm{o}} 12.305 / 10$ instituiu a logística reversa como um instrumento de desenvolvimento econômico e social caracterizado por um conjunto de ações, procedimentos e meios destinados a viabilizar a coleta e a restituição dos resíduos sólidos ao setor empresarial, para reaproveitamento, em seu ciclo ou em outros ciclos produtivos, ou mesmo outra destinação final ambientalmente adequada (BRASIL, 2010).

Visando obter subsídios para estudos relacionados à logística reversa, o objetivo do artigo é identificar na literatura brasileira o estado da arte das pesquisas sobre logística reversa de resíduos gerados na atividade agrossilvipastoril e agroindustrial de modo a ilustrar como o tema tem sido abordado nas pesquisas nacionais, quais suas contribuições para ampliar esses sistemas no agronegócio e quais as lacunas de pesquisas existentes sobre o tema. Para isto, realizou-se uma pesquisa aplicada, descritiva, exploratória e qualitativa por meio da técnica da revisão 
sistemática de literatura para levantamento do estado da arte sobre o tema. A revisão sistemática foi realizada com base no protocolo de Cronin, Ryan e Coughlan (2008), por meio de pesquisas em banco de dados nos sítios eletrônicos da Scielo, Spell, periódicos Capes, banco de teses e dissertações da Capes e complementarmente, no Google acadêmico, utilizando descritores relacionados à logística reversa de resíduos das atividades agrossilvipastoris e agroindustriais.

O artigo foi dividido em seis seções, sendo: (1) Introdução, (2) Referencial teórico, (3) Métodos e técnicas de pesquisa, (4) Apresentação, análise e discussão dos dados, (5) Considerações finais e, (6) Referências.

\section{REFERENCIAL TEÓRICO}

\subsection{DA LOGÍSTICA À LOGÍSTICA REVERSA}

A logística, tradicionalmente, é uma atividade de suporte a empresas e organizações para auxílio a projetar e administrar sistemas de controle do transporte e localização geográfica dos estoques de matérias-primas, de produtos em processo de fabricação e acabados pelo menor custo total (BOWERSOX et al., 2014). Dessa maneira, reforça Christopher (2009) que a logística se volta a um gerenciamento de um conjunto de atividades sob uma estratégia de planejamento desde a origem até seu consumo final.

Segundo Di Serio, Sampaio e Pereira (2006), essa nova dimensão do conceito envolve a integração de todas as atividades ao longo da cadeia de valores desde a geração de matérias-primas ao produto ou serviço até o cliente final, o que extrapola o enfoque operacional e adquire caráter estratégico.

Sob esse novo enfoque, segundo Guarnieri et al. (2006), a logística empresarial pode ser dividida em logística de suprimentos, logística de apoio à produção, logística de distribuição e logística reversa. Os fluxos diretos são direcionados ao cliente com o aporte da logística de produção, de distribuição e de suprimentos, tendo os custos incorporados e agregados ao valor do produto final. Já o processo logístico reverso aponta em direção oposta ao processo empresarial 
tradicional, o que pressupõe que poderá ter papel secundário de importância dentro das organizações já que normalmente esses custos não são incorporados ao produto final (GUARNIERI et al., 2006). Leite e Brito (2003) alertam que a falta de conhecimento dos ganhos potenciais associados aos canais reversos deve ser o principal impeditivo para que as empresas não optem pela sua adoção.

Nos anos mais recentes, os processos relacionados aos fluxos reversos têm ganhado maior importância no meio empresarial e acadêmico. Com o advento das preocupações ambientais emanadas pela sociedade, novos regulamentos são imputados a determinados setores e a logística reversa passou a estar relacionada, principalmente, ao reaproveitamento de embalagens e aspectos relacionados à reciclagem. Faria e Pereira (2012) tipificam que o processo de logística reversa se volta a matérias que possam ser reaproveitadas que retornam ao processo tradicional de suprimentos, produção e distribuição. Ratificando a relevância do processo de logística reversa, percebe-se aumento substancial no descarte de produtos e suas embalagens. Segundo Guarnieri et al. (2006), há aumento constante do nível de descartabilidade dos produtos em geral e decorre da redução do ciclo de vida dos produtos e maior giro dos estoques. Conclui Leite (2015), o aumento da velocidade logística e a exaustão dos sistemas tradicionais de disposição final têm forçado mais canais de fluxos reversos destinados à reciclagem, reúso e retorno ao ciclo de produção.

Atualmente, percebe-se que as principais linhas relacionadas à atração do processo de logística reversa estão relacionadas aos aspectos da sustentabilidade, vantagens econômicas e diferenciação nas relações com clientes e fornecedores. De Brito e Dekker (2002) determinaram como principais motivações a legislação ambiental, as vantagens econômicas, e a maior consciência dos consumidores, que acabam por exigir produção socioambientalmente adequada. Na mesma linha, Rogers e Tibben-Lembke (1999) adicionam a isso fatores de competição e diferenciação de novos mercados. Adicionalmente, Fuller e Allen (1995) consideram ainda três fatores determinantes para a implantação da logística reversa no âmbito estratégico e operacional, sendo eles: econômicos, quando voltados à viabilidade das operações e adaptações de processos para sua implantação e manutenção; tecnológicos, quando ligados às tecnologias disponíveis para reciclagem e reuso; e logísticos, quando 
se relacionam ao gerenciamento, na qual se definem as estruturas, os acordos e sistemas de recolhimento dos produtos.

Com a promulgação da lei 12.305/10, de 02 de agosto de 2010, que instituiu a Política Nacional dos Resíduos Sólidos (PNRS), a logística reversa se firma como instrumento de política pública para o desenvolvimento econômico e social para a coleta e a restituição dos resíduos sólidos com vistas ao aproveitamento em ciclos produtivos, ou outra destinação final ambientalmente adequada (BRASIL, 2010). A política preconiza a divisão de responsabilidades sobre o ciclo de vida dos produtos, imputando ao poder público o dever de incentivar e disponibilizar mecanismos para práticas da coleta seletiva de resíduos aos participantes, e os acordos setoriais necessários à logística reversa (BRASIL, 2010).

No que diz respeito às crescentes restrições que os marcos regulatórios exercem sobre as atividades produtivas e canais reversos, pode-se exemplificar como exemplo de sucesso no Brasil, a lei n. 9.974, de 2000, que dispõe sobre as diretrizes de gestão de embalagens de defensivos agrícolas, culminado como um dos países que mais retornam embalagens de agrotóxicos no mundo (DALEASTE; FRANCISCO; WINCK, 2016).

O desafio da ampliação dos sistemas de logística reversa será formar uma coalizão entre governos, sociedade e organizações com responsabilidades compartilhadas de modo a enxergar as vantagens competitivas e ambientais além dos limites legais (GUIMARÃES; RIBEIRO, 2016). Lopes e Tonini (2013) asseguram que os benefícios da logística reversa vão além das imposições legais instituídas e podem trazer benefícios concomitantes como, por exemplo, a elevação do ciclo de vida do produto, geração de benefícios ambientais e redução de custos de estocagem e armazenagem.

\subsection{RESÍDUOS AGROSSILVIPASTORIS E AGROINDUSTRIAIS}

Os resíduos oriundos das atividades agrossilvipastoris, sejam nos processos desenvolvidos no campo desde o plantio a colheita ou oriundos de consumo de insumos externos, ou mesmo, os gerados de atividades agroindustriais acabam por se tornarem igualmente problemáticos. Conforme previsão legal, o art. $1^{\circ} \mathrm{da}$ 
lei 12.305/10, de 02 de agosto de 2010, define resíduos agrossilvipastoris como: "os gerados nas atividades agropecuárias e silviculturais, incluídos os relacionados a insumos utilizados nessas atividades" (BRASIL, 2010). Da mesma forma, o crescimento da produção agropecuária associado a maior agroindustrialização da produção junto ao padrão de produção, baseado no consumo de insumos externos, tem gerado crescentes elevações de resíduos destas atividades. Cumpre destacar, que atividades mais intensivas e altamente geradoras de resíduos concentrados no processo produtivo decorrente do processo de agroindustrialização estão em expansão e vêm descortinando novos horizontes no Brasil principalmente na área dos bioprodutos e biocombustíveis (JUNQUEIRA; STERCHILE; DE LIMA, 2009). Esses fatores fazem que a cada ano aumente consideravelmente a produção de resíduos sólidos decorrentes das atividades agrossilvipastoris e agroindustriais tanto na forma orgânica como inorgânica (IPEA, 2012).

Dentre a gama de resíduos originados das atividades da agricultura, pecuária, aquicultura, silvicultura e as agroindústrias relacionadas, os que detêm origem orgânica revelam-se promissores ao aproveitamento, dado o potencial de formulação de insumos que serão diretamente aplicados ao campo como adubos, substratos, fertilizantes ou mesmo como fontes energéticas aproveitáveis (OVIEDO, 2005; BELLAVER, 2010). Desse modo, estes resíduos também são problemáticos quando descartados no meio ambiente de forma aleatória. Segundo Santos, Bellingieri e Freitas (2004), são evidentes os problemas causados pelo manejo inadequado desses resíduos para o meio ambiente, para a produção animal e para o homem, resultando em sérios prejuízos econômicos e sociais para o país, tanto no aspecto da degradação ambiental decorrente da eutrofização de corpos hídricos, quanto no aspecto dos custos de medidas de prevenção e tratamentos de saúde. No âmbito dos inorgânicos, grande parte dos gerados da atividade agrossilvipastoril é advinda do consumo de insumos externos, como embalagens de sementes, de adubos e agrotóxicos, frascos de produtos veterinários, dentre outros, o que exige das empresas fabricantes a responsabilidade compartilhada destes resíduos (BRASIL, 2016). 


\section{MÉTODOS E TÉCNICAS DE PESQUISA}

Essa pesquisa pode ser classificada conforme o proposto por Silva e Menezes (2001) do ponto de vista de sua natureza é aplicada; de acordo com seus objetivos, é considerada exploratória e descritiva; quanto à forma de abordagem do problema, classifica-se como qualitativa; e do ponto de vista dos procedimentos técnicos a pesquisa é uma revisão da literatura.

A revisão da literatura é considerada o início para uma pesquisa científica e se apresenta, geralmente, com caráter exploratório (WEBSTER; WATSON, 2002). Ainda conforme Webster e Watson (2002), a revisão bibliográfica deve ser executada de forma sistemática para sua confiabilidade e permitirá que outros pesquisadores possam fazer uso desses resultados com maior confiabilidade e ainda aproveitar outros estudos já concluídos.

O levantamento das pesquisas relacionadas à logística reversa nas atividades agrossilvipastoris e agroindustriais retrata o quadro atual da produção científica na tratativa do tema. Dito isso, a caracterização denominada estado da arte das pesquisas é levantada a partir da revisão de literatura sistemática realizada em diversos bancos de dados com reputação no meio acadêmico. Cabe destacar que o trabalho: A Produção Bibliográfica Brasileira sobre Logística Reversa no Setor de Agronegócios: Uma Revisão da Literatura (DUARTE; GUARNIERI; DINIZ, 2016) ilustra a utilização da revisão sistemática de literatura no âmbito do setor do agronegócio.

Para a revisão, o protocolo proposto por Cronin, Ryan e Coughlan (2008) foi o escolhido com vistas à realização da revisão sistemática de literatura. Cronin, Ryan e Coughlan (2008) preconizam que há dois tipos de revisão de literatura: (a) revisão tradicional ou narrativa da literatura; e (b) revisão sistemática da literatura. O primeiro tem como objeto principal dar subsídios ao pesquisador sobre aspectos globais de determinado entendimento de uma nova pesquisa, sem um critério mais rigoroso. O segundo, em contraste, permite uma abordagem com critérios definidos, delimitando os prazos em que a literatura foi selecionada, bem como os métodos utilizados para avaliar e sistematizar os resultados (CRONIN; RYAN; COUGHLAN, 2008).

Para garantir adequada confiabilidade e validade do método empregado, o autor deve precisar o critério utilizado na pesquisa seguindo as seguintes etapas: 
(i) formular a pergunta de pesquisa; (ii) definir critérios de inclusão ou exclusão;

(iii) selecionar e acessar a literatura; (iv) avaliar a qualidade da literatura incluída na avaliação; (v) analisar, sintetizar e divulgar os resultados (CRONIN; RYAN; COUGHLAN, 2008).

Dessa forma, são apresentadas as etapas do protocolo utilizado em detalhes:

- Definição da questão da pesquisa: Quais são e o que abordam os estudos atuais relacionados ao conceito ou a prática da logística reversa em resíduos das atividades agrossilvipastoris e agroindustriais no Brasil?

- Definição do conjunto de critérios de inclusão e exclusão: Os critérios foram as palavras-chave associadas aos operadores booleanos, bases de dados científicos, período de publicação e tipos de artigos. Como o estudo proposto trata de um tema multidisciplinar, podem se encontrar periódicos, teses ou dissertações em diversas áreas de conhecimento. Este artigo reproduz uma pesquisa realizada nas bases científicas: periódicos Capes, banco de teses e dissertações da Capes, Scielo e Spell. Considerando uma pesquisa exploratória nas bases citadas, verificou-se a escassez do tema, e assim optou-se por realizarse uma pesquisa complementar no Google Acadêmico, já que este sistema amplifica a pesquisa em diversos periódicos e bancos científicos diversos. A utilização de diversas bases de dados objetiva ampliar a variedade de estudos e, posteriormente, utilizar critérios objetivos para o refinamento e seleção dos mais representativos. Após a escolha das bases científicas para pesquisa, definiu-se o período de publicação, que se consideraram os últimos dez anos, abrangendo de 2005 a 2015 e, complementarmente, os surgidos em 2016. O período analisado foi definido para extrair o número de publicações sobre o tema nos cinco anos anteriores e posteriores a edição da lei $n^{0} 12.305 / 10$ que instituiu a Política Nacional de Resíduos Sólidos - PNRS. Desse modo, obtém-se um comparativo de publicações entre períodos similares de modo a se verificar se houve crescimento de geração de trabalhos acadêmicos após a referida legislação que instituiu a logística reversa como instrumento da PNRS. Os descritores foram definidos considerando as possíveis combinações, o termo logística reversa e resíduo como eixos base para a busca nas bases de dados. As combinações de palavras-chave para a busca nas bases Scielo e Spell foram 
aplicadas no campo resumo das publicações. Já nas bases Periódicos Capes e Banco de Teses e Dissertações da Capes, as combinações foram aplicadas em qualquer parte da pesquisa, pois essas bases não dispõem da opção do direcionamento do resumo para a busca. As combinações de busca foram: (a) logística reversa, resíduo, agrossilvipastoril; (b) logística reversa, resíduo, agroindústria; (c) logística reversa, resíduo, pecuária; (d) logística reversa, resíduo, agrícola; (e) logística reversa, resíduo, silvicultura; (f) logística reversa, resíduo, aquicultura. Com relação aos artigos selecionados definiuse que todos os publicados em periódicos ou em anais de eventos seriam considerados, excluindo-se, patentes, citações e capítulos de livros. O operador booleano utilizado foi o AND, excluindo os operadores OR e NOT, já que os resultados deveriam refletir artigos, teses e dissertações relacionados à logística reversa de resíduos na atividade agrossilvipastoril e agroindustrial.

- Seleção e acesso da literatura: Os resultados gerais utilizando as combinações das palavras-chave nas bases Periódicos Capes, Banco de Teses e Dissertações da Capes, Scielo, Spell retomaram teses, dissertações, artigos e artigos publicados em anais de eventos.

Na Tabela 1 é ilustrado o quantitativo de retornos de pesquisas obtidos com a aplicação das palavras-chave nas bases nacionais selecionadas.

Tabela 1. Número de pesquisas retornadas de acordo com os descritores

(Continua)

\begin{tabular}{|cccccc}
\hline Descritor & $\begin{array}{c}\text { Periódicos } \\
\text { Capes }\end{array}$ & $\begin{array}{c}\text { Banco de Teses e } \\
\text { Dissertaçóes da } \\
\text { Capes }\end{array}$ & Scielo & Spell & Total \\
\hline $\begin{array}{l}\text { Logística reversa } \\
\text { and resíduo and } \\
\text { agrossilvipastoril }\end{array}$ & 0 & 0 & 0 & 0 & 0 \\
$\begin{array}{l}\text { Logística reversa } \\
\text { and resíduo and } \\
\text { agroindústria }\end{array}$ & 1 & 30 & 1 & 0 & 32 \\
$\begin{array}{l}\text { Logística reversa and } \\
\text { resíduo and pecuária }\end{array}$ & 1 & 9 & 0 & 0 & 10 \\
\hline $\begin{array}{l}\text { Logística reversa and } \\
\text { resíduo and agrícola }\end{array}$ & 6 & 80 & 0 & 0 & 86 \\
\hline
\end{tabular}


(Conclusão)

\begin{tabular}{cccccc}
\hline Descritor & $\begin{array}{c}\text { Periódicos } \\
\text { Capes }\end{array}$ & $\begin{array}{c}\text { Banco de Teses e } \\
\text { Dissertaçóes da } \\
\text { Capes }\end{array}$ & Scielo & Spell & Total \\
\hline $\begin{array}{c}\text { Logística reversa and } \\
\text { resíduo and silvicultura }\end{array}$ & 1 & 10 & 0 & 0 & 11 \\
$\begin{array}{c}\text { Logística reversa and } \\
\text { resíduo and aquicultura }\end{array}$ & 0 & 4 & 0 & 0 & 4 \\
Total & 9 & 133 & 1 & 0 & 143 \\
\hline
\end{tabular}

Fonte: Esta pesquisa

Cabe salientar, quer as pesquisas retornadas do Google Acadêmico não foram demonstradas tendo em vista não se tratar de uma base de dados de periódicos mas como ferramenta de busca. Para a pesquisa realizada nesta ferramenta de busca, utilizaram-se os mesmos descritores combinados com o operador booleano AND entre os termos:

- Avaliação da qualidade da literatura incluída na revisão: Os artigos retornados com base nos descritores aplicados foram analisados com base no título, resumo ou na introdução de cada publicação com vistas à verificação se o tema está de acordo com o proposto neste artigo e como critério de inclusão na amostra. Para atender o tema em questão, analisou-se a presença de fluxos logísticos reversos de resíduos oriundos de atividade agrossilvipastoril ou agroindustrial, e caso não satisfeitas essas condições, os trabalhos foram excluídos da amostra. Considerando a pesquisa na base de dados do Portal de Periódicos Capes, nove artigos retornaram após a aplicação dos descritores, porém somente três foram selecionados para a amostra e, portanto, seis eliminados por não se mostrarem afins às temáticas relacionadas ao estudo proposto, após análises do título, resumo e introdução das publicações. Já no Banco de Teses e Dissertações da Capes, dos 133 estudos levantados, 27 foram selecionados e os demais excluídos por não se alinharem ao objetivo proposto após análise. No banco de dados do Scielo, somente um estudo foi identificado e este selecionado para a análise, e no portal do Spell, nenhuma publicação foi encontrada e, portanto, não 
houve nenhum artigo selecionado. No que tange à busca realizada no Google Acadêmico, 35 publicações foram identificadas no referido sistema de busca por se tratar de temas afetos aos descritores e operadores booleanos propostos. Destes, 27 são artigos completos, teses ou dissertações, e oito são de publicados em anais de eventos. Dentre a aplicação dos critérios de seleção e exclusão, a amostra deste artigo será composta por 66 pesquisas publicadas ou defendidas em programas de pós-graduação.

- Análise, síntese e disseminação dos resultados: Esta etapa demonstra a análise para cada artigo selecionado considerando o resumo, a introdução, a metodologia e a conclusão dos trabalhos selecionados nas bases de dados. Dessa forma, os dados foram tabulados em planilhas eletrônicas e classificados com os respectivos autores por ano de produção; desenho de pesquisa; local da pesquisa; produção acadêmica; grupo de produção agropecuária da aplicação da logística reversa; fatores determinantes para a aplicação da logística reversa no âmbito estratégico e operacional, propostos por Fuller e Allen (1995); origem dos resíduos; e periódico ou evento de publicação.

\section{APRESENTAÇÃO, ANÁLISE E DISCUSSÃO DOS DADOS}

Esta seção discute e apresenta os resultados da amostra. Os termos "logística reversa" e "resíduo" aparecem em 21 e 33 títulos, respectivamente, dos 66 estudos selecionados para a análise, seguidos por "embalagem" (17) e "agrotóxico" (16). Novamente, os termos "logística reversa" e "resíduo" se destacam e se apresentam mais frequentes quando se analisam as palavras-chave dos artigos da amostra, surgindo em 24 e 21 vezes, respectivamente, seguidos então, por "embalagem" (15), "agrotóxico" (13), "sustentabilidade" (10) e "ambiente" (10). Estes números já revelam que há predominância dos trabalhos relacionados a embalagens de agrotóxicos e afetos à temática ambiental quando se busca na literatura o tema da logística reversa em atividades agrossilvipastoris ou agroindustriais.

Considerando os objetivos dos 66 trabalhos selecionados para a amostra, o 
termo "resíduo" é o mais recorrente, com 41 detecções, seguido por "embalagem" (21), "agrotóxico" (19) e "logística reversa" (18).

Analisando a recorrência dos termos presentes nas estruturas principais dos trabalhos, presume-se que estudos relacionados à reciclagem ou reutilização de resíduos, especialmente os agroindustriais, nem sempre se relacionam ao conceito tradicional de logística reversa, já que há menor incidência do termo "logística reversa" frente ao "resíduo" nos objetivos analisados. O levantamento infere que o conceito de logística reversa no setor agrossilvipastoril está majoritariamente associado às embalagens de agrotóxicos pós-consumo, já que esse tema é consistentemente estudado e objeto de disposição legal pela lei $n^{0} 9.974 / 2000$, o que favorece o entendimento e a consolidação do termo junto aos autores.

Os artigos, as teses e as dissertações selecionados para a análise foram classificados por grupos de produtos do agronegócio a que se referem. Entretanto, as publicações referentes à logística reversa de resíduos relacionados a embalagens de agrotóxicos, mesmo esta não se caracterizando um produto do agronegócio, foram contabilizadas em separado por se tratar de tema específico e que abrange vários usos no setor de forma geral. Dessa forma, o levantamento apresentou as seguintes frequências: embalagens de agrotóxicos (18), cana-de-açúcar (7), coco (7), arroz (6), madeira (4), biodiesel (3), lácteos (2), palmito (2), outros produtos (18).

Pelos números contabilizados, percebe-se que o número de produtos do agronegócio é superior aos artigos selecionados, pois em um artigo, o arroz foi abordado conjuntamente com outro grupo classificado como "outros produtos". Cabe salientar que o levantamento destacado como "outros produtos" englobou produtos com frequência de um trabalho ou aquelas em que se abordaram vários resíduos agrossilvipastoris de maneira geral, não se classificando em nenhuma cadeia específica.

A partir das análises dos trabalhos, três categorias de enquadramento foram propostas segundo a área de investigação predominante baseados nos fatores determinantes para a aplicação da logística reversa no âmbito estratégico e operacional, propostos por Fuller e Allen (1995), sendo: aspectos tecnológicos de reaproveitamento; gerenciamento de resíduos; e análise de viabilidade técnica e econômica. No Quadro 1, estão discriminadas as categorias de abordagens 
encontradas nos trabalhos, em ordem decrescente de utilização por número de autores.

Quadro 1. Categorias de abordagem utilizadas na seleção

\begin{tabular}{|c|c|}
\hline CATEGORIAS & AUTORES \\
\hline $\begin{array}{l}\text { Gerenciamento de } \\
\text { resíduos }\end{array}$ & $\begin{array}{l}\text { Faria e Pereira (2012); Saidelles et al. (2012); Schwartz Filho (2006); Abreu, } \\
\text { Farias e Leite (2014); Almeida (2012); Dalesaste, Francisco e Winck (2015); } \\
\text { Halberstadt et al. (2015); Saltarin et al. (2013); Freitas, Hoppe e Murini } \\
\text { (2015); Guimarães (2015); Araújo (2011); Marques e Vieira (2015); Ferreira } \\
\text { Filho et al (2015); Frota (2016); Boldrin et al. (2007); Marques, Braga Junior } \\
\text { e Cataneo (2015); Brum e Henkes (2013); Lopes e Tonini (2013); Cometti } \\
\text { e Alves (2010); Toledo (2015); Campos, Lago e Oliveira (2013); Velasco } \\
\text { (2012); Seben (2011); Cometti (2011); Oliveira e Camargo (2014); Ladeiral, } \\
\text { Maehlerll e Nascimento (2012); Oliveira (2016); Carbone, Sato e Moori } \\
\text { (2005); Silva e Halberstadt (2012); Nogueira, Silva e Garcia (2013); Ferreira } \\
\text { Filho et al. (2011); Lopes et al. (2007). }\end{array}$ \\
\hline $\begin{array}{l}\text { Aspectos } \\
\text { tecnológicos de } \\
\text { reaproveitamento }\end{array}$ & $\begin{array}{l}\text { Bastos (2015); Trazzi (2011); Loss (2011); Cotinho Filho (2011); Oliveira } \\
\text { (2012); Camargo (2012); Pupo (2012); Casares (2012); Jesus (2012); Vicente } \\
\text { Junior (2012); Silva (2011); Costa (2012); Vilas Boas (2012); Fernandes } \\
\text { Filho (2012); Flach (2012); Alves (2011); Muruci (2012); Montenegro } \\
\text { (2012); Matter (2011); Castro (2011); Sora (2011); Gurgel (2012); Soares } \\
\text { Junior (2012); Poleto (2014); Borges (2014); Alves (2014); Teixeira (2005); } \\
\text { Jamas (2012). }\end{array}$ \\
\hline $\begin{array}{l}\text { Análise de } \\
\text { viabilidade técnica } \\
\text { e econômica }\end{array}$ & $\begin{array}{l}\text { Sellittol et al. (2013); Makishi (2012); Altoé e Voese (2014); Silva (2015); } \\
\text { Cornélio (2005); Barbosa et al. (2015). }\end{array}$ \\
\hline
\end{tabular}

Fonte: Esta pesquisa

Com base nos trabalhos citados no Quadro 1, cabe esclarecer que os aspectos tecnológicos referem-se a ensaios tecnológicos e testes experimentais direcionados a averiguar, desenvolver ou avaliar aspectos físicos, químicos e biológicos destinados à viabilidade para a reciclagem ou a reutilização de resíduos a partir do fluxo reverso. Segundo Leite (2015), a maior parte dos bens descartados reúne algumas condições necessárias para reintegração ao ciclo produtivo, como a tecnologia de reciclagem, ou o mercado para reaplicação e adaptação de materiais.

Quanto ao gerenciamento de resíduos, os autores foram reunidos nesta classificação em virtude de trabalhos relacionados ao manejo de resíduos desde a sua geração, sistema de coleta, gestão, estrutura e destinação final. O gerenciamento 
inclui planejamento, responsabilidades, práticas, procedimentos e recursos para desenvolver e implementar as ações necessárias ao cumprimento das etapas previstas em programas e planos, ou seja, envolve aspectos logísticos (SILVA; SANTOS; KLAMT, 2015). Já a categoria relacionada à análise da viabilidade técnica e econômica considerou pesquisas que se utilizaram de instrumentos e ferramentas para avaliação dos aspectos da viabilidade do uso dos resíduos e sua reinserção ao ciclo produtivo.

Considerando os resultados apresentados no Quadro 1, houve predomínio de pesquisas voltadas ao campo do gerenciamento de resíduos (32). Esse resultado já demonstra que a maior parte da amostra dedicou-se majoritariamente a investigar sistemas logísticos voltados aos fluxos reversos, verificando por meio de estudos de casos os fenômenos para entender as medidas, ações e arranjos a fim de proporcionar o retorno de embalagens utilizadas em atividades agrossilvipastoris. Ressalta-se que, nesta categoria, a investigação voltou-se em grande parte analisar a logística reversa de embalagens de agrotóxicos pós-consumo. Com relação à categoria dos aspectos tecnológicos de reaproveitamento, significativo número de pesquisas voltara-se também a esta investigação na amostra (28). Esse dado demonstra que boa parte a pesquisa acadêmica sobre o tema tem se dedicado a analisar e desenvolver atributos específicos que possam proporcionar tecnologias de reaproveitamento de resíduos. Ressalta-se que a totalidade de pesquisas enquadradas nessa categoria utilizou-se de métodos experimentais, o que é dedutível, já que avaliar atributos tecnológicos requerem medições, ensaios, testes e delineamentos experimentais principalmente. Por fim, as pesquisas que se inseriram na categoria de avaliação de viabilidade técnica e econômica foram pouco detectadas (6). Esse parâmetro já aporta indícios que existem lacunas de pesquisas voltadas ao desenvolvimento de viabilidades para se estabelecer fluxos reversos em situações práticas e operacionais em setores ou atividades empresariais.

Em relação às origens dos resíduos, se na atividade agrossilvipastoril ou agroindustrial, há predomínio de estudos de logística reversa de resíduos agroindustriais (43) frente aos de atividades agrossilvipastoris (23). Isto evidencia que quando se tem um ambiente centralizado com alta geração de resíduos, como as agroindústrias, é melhor aplicável à viabilidade de retorno ao fluxo reverso do que 
quando estabelecidos em atividades de produção agrossilvipastoril, esta geralmente mais dispersa no ambiente rural.

Considerando somente os resíduos advindos das atividades agrossilvipastoris, o estado da arte revela a predominância de trabalhos com foco para resíduos provenientes de embalagens de insumos externos (18) e somente cinco relacionados à geração de resíduos orgânicos de atividades de produção agropecuária. Dentre os insumos externos, a totalidade se constituiu de embalagens de agrotóxicos, não se identificando nenhum outro tipo de resíduo advindo do consumo de insumos externos à propriedade. Já os demais resíduos oriundos da atividade de produção agropecuária, dos cinco totais, três estão relacionados à criação animal intensiva e somente dois relacionam-se às atividades de produção vegetal.

Esse dado permite verificar lacunas evidentes na literatura quando se analisa a logística reversa das atividades agrossilvipastoris, já que poucos trabalhos evidenciaram o aproveitamento de resíduos orgânicos oriundos da atividade de criação animal ou exploração vegetal no ambiente rural. Ainda mais evidente é o fato de que os resíduos oriundos de insumos externos basearam-se na totalidade por embalagens de agrotóxicos, não se verificando outros resíduos como embalagens de produtos veterinários, sementes e adubos, muito comuns em propriedades rurais.

Quanto às regiões onde os estudos se desenvolveram, o Gráfico 1 ilustra a quantidade de trabalhos por Estados da Federação encontrados na amostra.

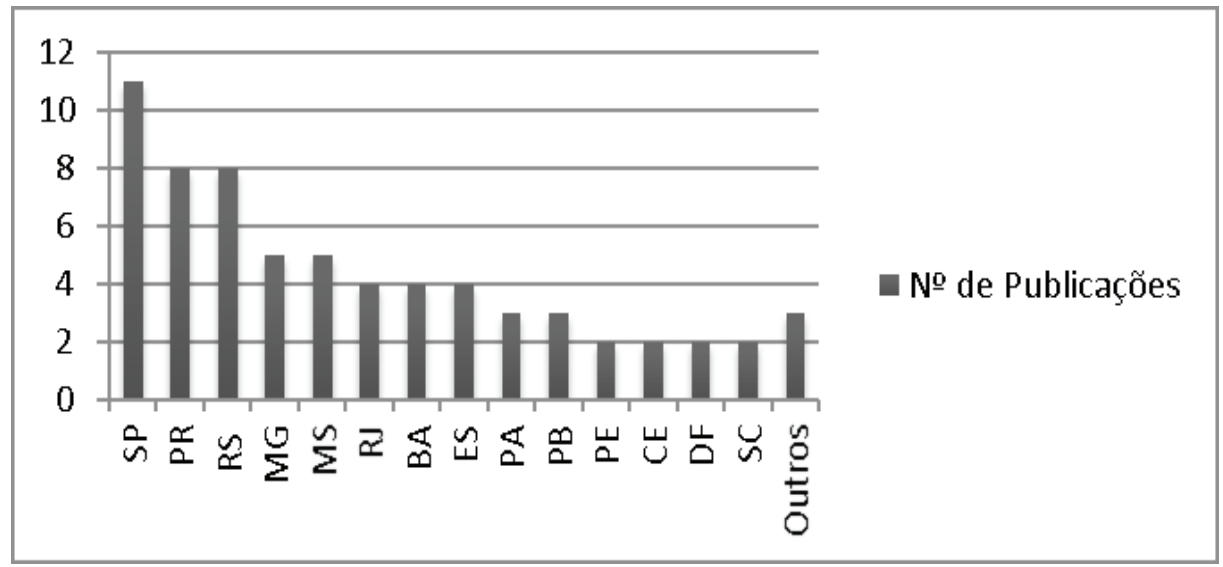

Gráfico 1. Quantidade de estudos por Estados (de 2005 a 2016) Fonte: Esta pesquisa 
O Gráfico 1 revela informações referentes à concentração de estudos afins ao tema proposto neste artigo. A maior parte dos trabalhos da amostra concentramse nas regiões Sul e Sudeste do Brasil (42/66), com destaque para SP (11), PR (8) e RS (8). A região Norte foi a que apresentou menor quantidade de estudos e baixa representatividade, com somente dois Estados onde se registraram trabalhos na área, sendo PA (3) e TO (1). Em relação à categoria classificada como "outros", esta reuniu demais trabalhos de regiões que apresentaram somente uma publicação.

O número de publicações referentes ao estado da arte da logística reversa dos resíduos agrossilvipastoris e agroindustriais nos últimos dez anos mostra a tendência de elevação durante o período considerado que se iniciou em 2005. Entretanto, o crescimento é mais expressivo logo após o ano de 2010, possivelmente após a publicação da lei $\mathrm{n}^{\mathrm{o}}$ 12.305/10 que instituiu a Política Nacional de Resíduos Sólidos - PNRS, o que pode ter despertado interesses da comunidade acadêmica sobre o assunto. No Gráfico 2 é apresentada a quantidade de pesquisas produzidas por ano considerando a amostra analisada.

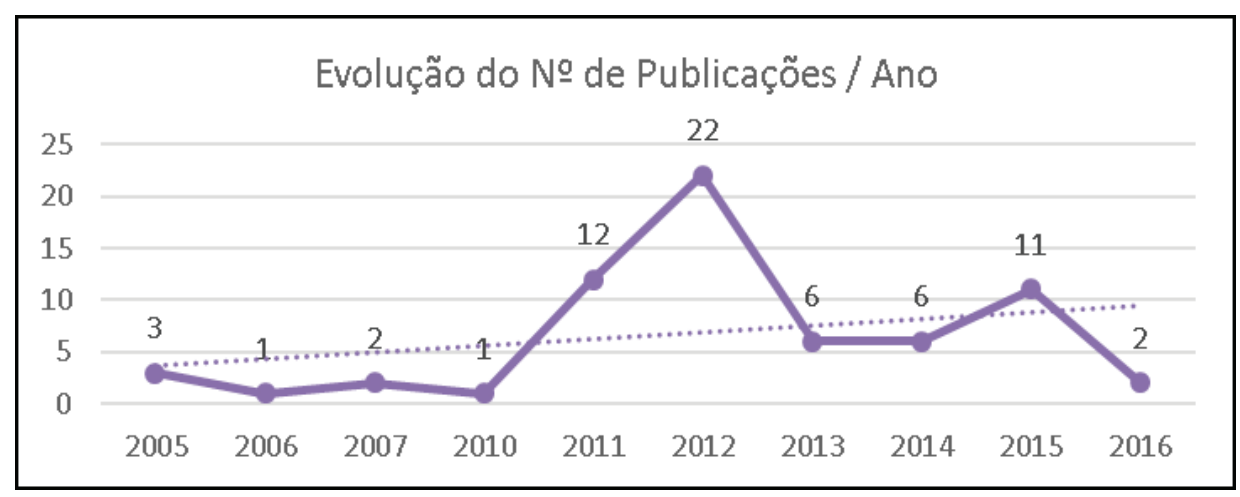

Gráfico 2. Quantidade de estudos por ano - período de 2005 a 2016. Fonte: Esta pesquisa

Pelo Gráfico 2 visualiza-se a elevação na quantidade de estudos elaborados atingindo o pico no ano de 2012, ano em que foram produzidos 22 estudos. Com relação ao ano de 2016, no período de conclusão do trabalho, somente dois trabalhos compuseram a análise, porém a linha de tendência traçada evidencia 
uma tendência de elevação de estudos relacionados à logística reversa dos resíduos agrossilvipastoris e agroindustriais.

Por comparativo ao período antes e após a publicação da lei 12.305 de 2010 que institui a PNRS, verifica-se a elevação na quantidade de artigos relacionados à logística reversa. Dessa forma, há somente sete publicações relacionadas ao tema desde 2005 até o fim de 2010, frente a 59 publicações após esse período até o ano de 2016. Dessa maneira, têm-se números crescentes significativos sobre o tema após a promulgação da referida lei.

Em que pese a natureza de pesquisa, $47 \%$ (31) dos estudos selecionados adotaram a abordagem predominantemente qualitativa e 45\% (30) a quantitativa, enquanto apenas $8 \%$ (5) combinaram ambas as abordagens, denominadas de "qualiquanti". A natureza de pesquisa se mostrou equilibrada quando se refere às pesquisas qualitativas e quantitativas separadamente, evidenciando baixo uso conjunto de naturezas mistas para obtenção dos resultados alvos das pesquisas.

Considerando o total de publicações em revistas presentes na amostra (20), nota-se que a maior parte refere-se a periódicos relacionados ao meio ambiente e à sustentabilidade (10), demonstrando caráter alinhado a essas temáticas. Em menor número, os artigos da amostra estão ligados à área de produção, administração ou economia (4 periódicos). Já os demais periódicos contêm publicações multidisciplinares (6). Considerando as publicações em anais de eventos (8), há maior número de publicações após o ano de 2011, seis trabalhos, e somente dois, foram publicados anteriormente a este período desde 2005.

Em relação às teses e dissertações presentes na amostra, percebe-se que maior parte das universidades tratou do tema de forma pontual com somente uma publicação e poucas produziram mais de um estudo por instituição. Como exemplo de instituições que trataram do tema mais de uma vez, a Universidade de São Paulo e Universidade Federal do Espírito Santo apresentaram três teses ou dissertações defendidas, e outras seis universidades que trataram do tema somente em duas publicações. A maior frequência de trabalhos pode indicar que a logística reversa está sendo tratada em uma linha de pesquisa nessas universidades. 


\section{CONSIDERAÇÕES FINAIS}

Considerando uma análise geral dos estudos selecionados, percebe-se predomínio de estudos da logística reversa relacionados ao retorno das embalagens de agrotóxicos. Este resultado pode ser explicado por ser uma atividade legalmente regulamentada e obrigatória e com práticas de fluxos reversos já praticados desde 0 ano de 2000 no Brasil, regulados pela lei n. 9.974/2000 que prevê o recolhimento e destinação adequada de embalagens de agrotóxicos. Cabe ressaltar que a partir daí o Brasil tornou-se exemplo mundial na logística reversa de embalagens de agrotóxicos, obtendo um percentual de 91\% de reciclagem destas em 2014, conforme informações do INPEV (2014). Porém, outras embalagens oriundas de insumos externos para a produção agropecuária não obtiveram abordagens nas pesquisas da amostra analisada.

Conquanto, quando se analisam os resíduos oriundos da atividade agroindustrial, as práticas de logística reversa foram fortemente abordadas sobre os resíduos orgânicos oriundos de processamentos industriais, bem como sua destinação predominante à reciclagem ou ao reprocessamento para fins energéticos, reintegrando o ciclo produtivo industrial.

O estado da arte da logística reversa no Brasil com foco nos resíduos agrossilvipastoris e agroindustriais foi classificado de acordo com fatores determinantes para a aplicação da logística reversa no âmbito estratégico e operacional em três grandes categorias de enquadramento: aspectos tecnológicos de reaproveitamento; gerenciamento de resíduos; e análise de viabilidade técnica e econômica. Dentre as categorias, verificou-se maior número de estudos voltados ao gerenciamento, seguidos dos aspectos tecnológicos e, por fim, as análises de viabilidade técnica e econômica. Os resultados desta categorização refletem que os trabalhos ligados ao tema têm se dedicado predominantemente a ações de gerenciamento voltadas a sistemas de retorno de resíduos ao processo produtivo ou à destinação final adequada a partir de processos que permitam diagnósticos, estruturas logísticas, acordos, sistemas de recolhimento e arranjos gerais para essa finalidade.

Também se constatou neste estado da arte, muitos estudos ligados a processos de análises, desenvolvimento e aprimoramento de tecnologias destinadas 
à reciclagem e ao reúso de resíduos, mostrando-se mais significativos nos estudos quantitativos e experimentais comumente utilizados nas teses ou dissertações da amostra. Dentre as categorias para a logística reversa no âmbito estratégico e operacional, houve baixa produção científica para análises da viabilidade técnica e econômica, um paradoxo, já que a nova orientação da PNRS insere instrumentos nesta linha de ação para se estabelecer os acordos setoriais.

O presente trabalho indica lacunas na literatura para o desenvolvimento futuro de pesquisas, sendo eles: (a) logística reversa de embalagens de insumos externos utilizados na atividade agrossilvipastoril, exceto embalagens de agrotóxicos; (b) estudos de viabilidade técnica e econômica sobre a logística reserva de resíduos visando subsidiar conhecimentos necessários à implantação e na promoção para a formalização dos acordos setoriais previstos na PNRS; e (c) reutilização de resíduos orgânicos provenientes das atividades agrossilvipastoris, como exemplo, oriundos da produção e beneficiamento da soja, milho, trigo, arroz, laranja, dejetos provenientes da pecuária, dentre outros, nos quais poderão ser insumos para produção de biocombustíveis, biofertilizantes, materiais da construção civil, cosméticos e artefatos em geral.

Por fim, como limitações deste trabalho, a pesquisa se restringiu a consultas bibliográficas em bases de artigos, teses e dissertações abrigadas por meio de alguns portais acadêmicos nacionais, excluindo artigos internacionais que já tratam do tema com mais profundidade. Ademais, os trabalhos objeto desta análise são relativos à logística reversa de resíduos das atividades agrossilvipastoris e agroindustriais, limitando-se ao processo pós-consumo do setor já que seu foco é os resíduos gerados nestas atividades. Cumpre destacar, que é provável que existam inúmeros outros estudos relacionados à logística reversa em outros setores econômicos, e também, ao fluxo pós-venda, portanto não considerados neste trabalho.

\section{REFERÊNCIAS}

BELLAVER, C. Alternativa sustentável para os resíduos industriais: compostagem acelerada. Graxaria brasileira: indústria de farinha e gordura animal, São Paulo, v. 3, n. 17, set./out. 2010. 
BOWERSOX, D. J. et al. Gestão logística da cadeia de suprimentos. Porto Alegre: AMGH, 2014.

BRASIL. Lei $\mathrm{n}^{\mathrm{o}}$ 12.305, de 02 de agosto de 2010. Institui a Política Nacional de Resíduos Sólidos. Altera a Lei no 9.605, de 12 de fevereiro de 1998; e dá outras providências. Disponível em: <http://www.planalto.gov.br/ccivil_03/_ato20072010/2010/lei/112305.htm> Acesso: 16 jun. 2016.

BRASIL. Ministério do Meio Ambiente, dos Recursos Hídricos e da Amazônia Legal. Logística reversa. Disponível em:<http://www.mma.br> . Acesso: 02 jun. 2016

CEPEA - Centro de Estudos Avançados em Economia Aplicada. PIB do Agronegócio (2015). Disponível em:<http://www.cepea.esalq.usp.br/pib/> Acesso: 27 mar. 2017.

CHAVES, G. L. D.; ALCÂNTARA, R. L. C. Logística reversa: uma análise da evolução do tema através de revisão da literatura. In: ENCONTRO NACIONAL DE ENGENHARIA DE PRODUÇÃO - ENEGEP, 29, 2009. Anais... Salvador - BA, 2009.

COMETTI, J.L.S. Logística reversa das embalagens de agrotóxicos no Brasil: um caminho sustentável? 2009. Dissertação (Mestrado) - Universidade de Brasília, Brasília, 2009.

CHRISTOPHER, M. Logística e gerenciamento da cadeia de suprimentos: criando redes que agregam valor. 2. ed. São Paulo: Cengage Learning, 2009.

CRONIN, P.; RYAN, F.; COUGHLAN, M. Undertaking a literature review: a step-by step approach. British Journal of Nursing, v. 17, n.1, 38-43, 2008.

DALEASTE, J.; FRANCISCO, R.; WINCK, C. A.; Logistica reversa: uma estratégia empresarial na coleta de embalagens vazias de agrotóxicos. Unincor, v. 14, n. 1,2016.

DE BRITO, M. P., DEKKER, R. Reverse logistics: A framework. Econometric Institute Report EI 2002-38. Erasmus University Rotterdam, Econometric Institute, 2002.

DI SERIO, L. C.; SAMPAIO, M.; PEREIRA, S. F. A evolução dos conceitos de logística: 
um estudo na cadeia automobilística no Brasil. In: ENCONTRO DA ASSOCIAÇÃO NACIONAL DE PÓS-GRADUAÇÃO E PESQUISA EM ADMINISTRAÇÃO, 30., 2006, v. 1. Salvador. Anais... ENANPAD, 2006.

DUARTE, S.C.L.; GUARNIERI, P.; DINIZ, J.D.A.S. A Produção Bibliográfica Brasileira Sobre Logística Reversa no Setor de Agronegócios: Uma Revisão da Literatura. CONGRESSO DE ECONOMIA, ADMINISTRAÇÃO E SOCIOLOGIA RURAL, 54. Maceió, Alagoas. Anais... SOBER, 2016.

FARIA, A. C.; PEREIRA, R. S. O processo de logística reversa de embalagens de agrotóxicos: um estudo de caso sobre o INPEV. Organizações Rurais \& Agroindustriais, v. 14, n. 1, p. 127-141, 2012.

FULLER, D. A.; ALLEN, J. Reverse Channel Systems in Polonsky. 1995.

GUARNIERI, P. et al. WMS - Warehouse Management System: adaptação proposta para o gerenciamento da logística reversa. Revista Produção, v. 16, n. 1, p. 126139, abr. 2006.

GUIMARÃES, K.; RIBEIRO, F. Logística Reversa de embalagens em geral: avaliação do acordo setorial a partir das recomendações internacionais. ENGEMA. 2016.

INSTITUTO DE PESQUISA ECONÔMICA APLICADA - IPEA. Diagnóstico dos Resíduos Orgânicos do Setor Agrossilvipastoril e Agroindústrias Associadas: Relatório de Pesquisa. Brasília, 2012.

INSTITUTO DE PESQUISA ECONÔMICA APLICADA - IPEA. Diagnóstico dos Resíduos Sólidos do Setor Agrossilvipastoril: Resíduos Sólidos Inorgânicos. Relatório de Pesquisa. Brasília, 2013.

INPEV - Relatório de Sustentabilidade 2014. Disponível em: < http://inpev.org.br/ saiba-mais/publicacoes/relatorio-de-sustentabilidade/relatorio-de-sustentabilidade, 2014>. Acesso: 26 jun. 2016.

JACOBI, P.R.; BESEN, G.R. Gestão de resíduos sólidos em São Paulo: desafios da sustentabilidade. Estud. Av., v. 25, n. 71, p. 135-158. 2011. 
JUNQUEIRA, C. P.; STERCHILE, S. P. W.; DE LIMA, J.F. O crescimento econômico agrícola dos Estados da Região Sudeste do Brasil - 1995/2005. Organizações Rurais \& Agroindustriais, Lavras, v. 11, n. 3, p. 407-419, 2009.

LEITE, P. R.; BRITO, E. P. Z. Reverse logistics of returned products: is Brazil ready for the increasing challenge. In: BUSINESS ASSOCIATION OF LATIN AMERCIAN STUDIES. Anais... São Paulo: BALAS, 2003.

LEITE, P.R. Logística reversa: meio ambiente e competitividade. São Paulo: Prentice Hall, 2015.

LOPES, A. C. V.; TONINI, M. C. S. M. A Logística Reversa com embalagens vazias de agrotóxico: um estudo na associação de revendedores de agrotóxico no Brasil. Organizações e Sustentabilidade, Londrina, v. 1, n. 1, p. 54-72, jul./dez. 2013.

OVIEDO, M. P. Bagaço de uva: produto nobre na alimentação humana. 2005. Disponível em: <http://noticias.universia.com.br/ciencia-ecnologia/ noticia/2005/07/18/470317/bagaouva-produto-nobre-na-alimentao-humana.html $>$. Acesso em: 27 mar. 2017.

ROGERS, D. S.; TIBBEN-LEMBKE, R. Going backwards: reverse logistics, trends and practices. Universtity of Nevada, Reno: Center for Logistics Management, 1999.

SANTOS, C. C.; BELLINGIERI, P. A.; FREITAS, J. C. Effect of the application of chicken litter composts on chemical properties of a Typic Haplorthox soil cultivated with sorghum [Sorghum bicolor (L.) Moench]. Científica, Jaboticabal, v. 32, n. 2, p. 134$140,2004$.

SILVA, E. L.; MENEZES, E. M. Metodologia da pesquisa e elaboração de dissertação. 3. ed. rev. e atual. Florianópolis: Laboratório de Ensino a Distância da UFSC, 2001.

SILVA, F. C.; SANTOS, F. F.; KLAMT, R. A. Ações para o gerenciamento ambientalmente adequado dos resíduos gerados na construção de edificações. Revista Saúde e Meio Ambiente - RESMA, v. 1, p. 1-23, 2015. 
SPADOTTO, C.; RIBEIRO, W. Gestão de Resíduos na Agricultura e Agroindústria. São Paulo. Fundação de Estudos e Pesquisas Agrícolas e Florestais - FEFAP, 2006.

WEBSTER, J.; WATSON, J.T. Analyzing the past to prepare for the future: writing a literature review. MIS Quarterly \& The Society for Information Management, v. 26, n. 2, p. 13-23, 2002.

Recebido em: 10/11/2016 Aceito em: 16/06/2017 